\title{
Estudo comparativo do desempenho mecânico da sílica ativa e do metacaulim como adições químicas minerais em estruturas de concreto
}

\section{(Comparative study of mechanical performance of silica fume and metakaolin mineral admixtures in concrete structures)}

\author{
J. B. M. do Carmo' ${ }^{1}$ K. F. Portella ${ }^{2}$ \\ ${ }^{1}$ Programa Interdisciplinar de Pós-Graduação em Engenharia-PIPE, Centro Politécnico, Universidade Federal \\ do Paraná, Curitiba, PR 81531-980 \\ ${ }^{2}$ LACTEC/DPTM, Instituto de Tecnologia para o Desenvolvimento, C. P. 19.067, Curitiba, PR 81531-980 \\ portella@lactec.org.br,kfportella@hotmail.com
}

\begin{abstract}
Resumo
Neste trabalho foram realizados estudos comparativos entre um concreto convencional e concretos contendo sílica ativa e metacaulim de alta reatividade (MCAR). O desempenho dos mesmos foi testado em termos das resistências à compressão e à tração por compressão diametral. Análises de custo foram efetuadas comparativamente, em função da resistência à compressão, do consumo de materiais cimentícios e, também, do preço do produto no mercado brasileiro. Os consumos totais de materiais cimentícios estudados estiveram compreendidos entre $180 \mathrm{~kg} / \mathrm{m}^{3}$ e $650 \mathrm{~kg} / \mathrm{m}^{3}$. O uso de $8 \%$ em peso de MCAR e de sílica ativa em relação à massa de cimento, foi suficiente para inibir as reações álcali-agregado verificadas no concreto convencional. O uso de ambas as adições proporcionou ganhos em termos de resistência e de custo nas primeiras idades ( 90 dias), sendo, praticamente equivalentes entre si.

Palavras-chave: concreto, sílica ativa, metacaulim.
\end{abstract}

Abstract

A comparative study between reference-concrete $(R C)$, silica fume (SF) and high reactivity metacaulim (MCAR) was done. The performances were tested in terms of the compressive and tensile strength by diametrical compression. Comparative cost analyses were carried out by taking into account the binders consumption at the same strength, and also the Brazilian product prices. The total consumptions of cimentitious materials studied were in the range of $180 \mathrm{~kg} / \mathrm{m}^{3}$ to $650 \mathrm{~kg} / \mathrm{m}^{3}$. The replacement of $8 \%$ (w/w) of $M C A R$ and SF over cement weight was enough to inhibit alkali-aggregate reaction, investigated whitout cement admixtures. Both additions provided bennefit in terms of cost and mechanical resistance in the first ages (90 days), been equivalently.

Keywords: concrete, silica fume, metakaolin.

\section{INTRODUÇÃO}

Em grandes obras estruturais como barragens de usinas hidroelétricas, há a necessidade de se utilizar concretos que atendam às especificações técnicas com a obtenção do menor custo e sem comprometimento da qualidade final. Para tanto, vêm sendo desenvolvidas diversas pesquisas experimentais com adições químicas minerais e orgânicas nas dosagens de concretos convencionais, tais como a sílica ativa, resinas poliméricas, fibras, borrachas e escórias de alto forno [1-7].

$O$ benefício em se utilizar tais produtos centra-se no aspecto tecnológico, observando que todas as propriedades do concreto convencional sejam, no mínimo, mantidas ou melhoradas. Com relação ao aspecto ambiental, buscamse reduções na quantidade dos aglomerantes hidráulicos usados, aumento da durabilidade e o uso de subprodutos industriais que estejam saturando os aterros sanitários dos grandes centros urbanos $[2,4,8,9]$.
As adições minerais podem ser classificadas em função da sua composição química e mineralógica [3], em: i) escória granulada de alto-forno, pertencente ao grupo dos silicatos vítreos contendo, principalmente, cálcio, magnésio, alumínio e sílica, com tamanhos médios de partículas menores do que $45 \mu \mathrm{m}$ e finura Blaine de $500 \mathrm{~m}^{2} / \mathrm{kg}$; ii) cimentante e pozolânico ou cinzas volantes, o qual contém alto teor de óxido de cálcio $(\mathrm{CaO}>10 \%) ; 10 \%$ a $15 \%$ da distribuição média do tamanho de partículas maior do que $45 \mu \mathrm{m}$ e finura Blaine compreendida entre $300 \mathrm{~m}^{2} / \mathrm{kg}$ e 400 $\mathrm{m}^{2} / \mathrm{kg}$. É constituida, na sua maior parte, por silicatos vítreos contendo, principalmente, cálcio, magnésio, alumínio e álcalis. A pequena quantidade de matéria cristalina presente consiste, geralmente, de quartzo e aluminatos de cálcio do tipo $3 \mathrm{CaO} . \mathrm{Al}_{2} \mathrm{O}_{3}$ ou $\mathrm{C}_{3} \mathrm{~A}$. Podem estar presentes cal livre $(\mathrm{CaO})$ e periclásio $(\mathrm{MgO})$; iii) pozolanas comuns, normalmente, constituídas por cinzas volantes de baixo teor de cálcio $(\mathrm{CaO}<10 \%)$ e, por materiais naturais, com teores entre $15 \%$ 
e $30 \%$ de partículas com diâmetro médio $>45 \mu \mathrm{m}$ e finura Blaine entre $250 \mathrm{~m}^{2} / \mathrm{kg}$ e $350 \mathrm{~m}^{2} / \mathrm{kg}$. São, também, silicatos vítreos de alumínio, ferro e álcalis. A pequena quantidade de matéria cristalina presente consiste, geralmente, de quartzo, mulita, silimanita, hematita e magnetita. A maior parte das partículas são esferas sólidas com textura rugosa e diâmetro médio da ordem de $20 \mu \mathrm{m}$; e, iv) altamente pozolânicas, tendo como representantes atuais: (a) sílica ativa, na forma amorfa e com diâmetro médio de partículas entre $0,1 \mu \mathrm{m}$ e $5,5 \mu \mathrm{m}$; (b) cinza de casca de arroz produzida por combustão controlada, com diâmetro médio de partículas da ordem de $1,5 \mu \mathrm{m}$ e superfície específica de $16.800 \mathrm{~m}^{2} / \mathrm{kg}$. Esses materiais têm grande potencial de uso no Brasil, uma vez que seu teor na casca do arroz beneficiado pode chegar a, aproximadamente, $4 \%$ em peso [8]; e, (c) metacaulim com superfície específica em torno de $60.000 \mathrm{~m}^{2} / \mathrm{kg}$ e com partículas altamente lamelares.

Além dos aspectos ambientais, a adição de pozolanas em concreto tende refletir uma série de outros benefícios, tais como: i) tecnológicos, pelo aumento da trabalhabilidade resultante, redução do consumo de água para o mesmo valor de abatimento, ampliação da durabilidade da estrutura ou melhoria das propriedades mecânicas; ii) econômicos, pela diminuição do consumo do aglomerante hidráulico por ser um dos insumos de mais alto custo em uma obra; e, iii) ecológicos, uma vez que grande parte das pozolanas provém de resíduos de processos industriais e cujo destino é o aterro sanitário.

\section{Princípio da ação das pozolanas no concreto}

No que se refere à ação química, as pozolanas reagem com o hidróxido de cálcio $\left(\mathrm{Ca}(\mathrm{OH})_{2}\right), \mathrm{CH}$, produzido durante a hidratação do cimento Portland. Como resultado, tem-se a produção de fases químicas com maior estabilidade e poder aglomerante, sendo os principais responsáveis pela resistência das pastas de cimento hidratadas. A atividade pozolânica tem origem na instabilidade termodinâmica existente quando estes materiais entram em contato com a água saturada de $\mathrm{CH}$, haja vista que a sílica e a alumina existentes na pozolana pertencem a estruturas facilmente deslocáveis (estruturas amorfas ou desordenadas) $[2,4,5,9$, 10]. O uso de pozolanas, mesmo em pequenas quantidades, é capaz de consumir quase que completamente o $\mathrm{CH}$ produzido na hidratação do cimento Portland comum. A transformação do $\mathrm{CH}$ em silicato de cálcio hidratado (CSH) faz com que o concreto se torne mais resistente ao ataque ácido e ao ataque por sulfatos. Contudo, é interessante ressaltar que o CSH formado na reação pozolânica tende a apresentar menor densidade que o CSH formado na hidratação do cimento [2]. As adições de pozolanas tipo sílica ativa e sílica obtida da calcinação da casca de arroz em proporções de até $30 \%$ resultaram, normalmente, na diminuição do $\mathrm{pH}$ médio do eletrólito do concreto. Este efeito foi utilizado para a produção de recifes artificiais marinhos e blocos cúbicos, objetivando estudos ambientais na plataforma continental paranaense (hidrografia, plâncton, bentos e nécton) e a criação de um sistema de substratos em concreto para a conservação da biodiversidade marinha, ampliando a área de pesca artesanal e, desta forma, contribuindo com o desenvolvimento sócioeconômico das populações litorâneas do Estado do Paraná [11]. Quanto à ação física, a sua adição pode ocasionar um aumento da massa específica da mistura, pelo efeito de preenchimento dos vazios (efeito microfiler) e, também, pela densificação da zona de transição entre a pasta de cimento e o agregado devido à interferência na movimentação das partículas de água livre em relação aos sólidos da mistura. $[2,9,12-14]$.

\section{Tipos de pozolanas altamente reativas}

Sílica ativa: a sílica ativa é, normalmente, oriunda do processo de produção das indústrias de ferrosilício e silíciometálico [2]. Neste processo, o silício é produzido em grandes fornos elétricos de fusão, do tipo arco-voltaico, onde o quartzo é reduzido pelo carbono em altas temperaturas. Como resultado tem-se a produção do monóxido de silício gasoso $(\mathrm{SiO})$, que se condensa às temperaturas mais baixas, formando o dióxido de silício $\left(\mathrm{SiO}_{2}\right)$. Este apresenta uma coloração que pode variar do cinza claro ao escuro, devido aos teores de carbono incombusto presentes [3]. A sua produção anual encontra-se em torno de 1 milhão de toneladas, sendo os maiores produtores a Noruega e os Estados Unidos [2]. O teor de $\mathrm{SiO}_{2}$ presente nesta pozolana fica, invariavelmente, em patamares próximos a $80 \%$, sendo que este teor está diretamente relacionado com a forma de produção existente. As indústrias que adotam o teor de silício na ordem de $75 \%$ produzem um rejeito com teores entre $85 \%$ e $90 \%$ de $\mathrm{SiO}_{2}$ não-cristalina, enquanto que, nas indústrias que adotam um menor teor de silício (50\%), o rejeito apresenta uma quantidade inferior de sílica não-cristalina, tornando-a menos reativa [2]. Na Noruega é adotado o teor mínimo de $85 \%$ de $\mathrm{SiO}_{2}$ para seu uso em concretos [5]. E, no Brasil, este é fixado em $85 \%$ para o $\mathrm{SiO}_{2}$ não-cristalino [15]. As principais impurezas verificadas neste rejeito industrial são os álcalis $\mathrm{K}_{2} \mathrm{O}$ e $\mathrm{Na}_{2} \mathrm{O}$, onde o primeiro encontra-se em teores entre $1 \%$ e $5 \%$, e o $\mathrm{CaO}$ e o $\mathrm{MgO}$ em teores inferiores a $2 \%$ [16].

Tabela I - Composição química da sílica ativa proveniente de alguns processos metalúrgicos [11].

[Table I - Silica fume chemical compositions from some metallurgical processes [11].]

\begin{tabular}{cccc}
\hline Material & $\begin{array}{c}\text { Sílica ativa } \\
\text { (ind. silício- } \\
\text { metálico) }\end{array}$ & $\begin{array}{c}\text { Sílica ativa } \\
\text { (ind. ferro- } \\
\text { silício) }\end{array}$ & $\begin{array}{c}\text { Sílica ativa } \\
\text { (ind. ferro- } \\
\text { silício) }\end{array}$ \\
\hline $\mathrm{SiO}_{2}$ & 94,00 & 90,00 & 83,00 \\
$\mathrm{Al}_{2} \mathrm{O}_{3}$ & 0,06 & 1,00 & 2,50 \\
$\mathrm{Fe}_{2} \mathrm{O}_{3}$ & 0,03 & 2,90 & 2,50 \\
$\mathrm{CaO}$ & 0,50 & 0,10 & 0,80 \\
$\mathrm{MgO}$ & 1,10 & 0,20 & 3,00 \\
Álcalis & 0,10 & 2,20 & 2,30 \\
Perda ao fogo & 2,50 & 2,70 & 3,60 \\
\hline
\end{tabular}


Os teores típicos dos principais elementos que constituem a sílica ativa encontram-se listados na Tabela I [9].

Metacaulim: este material foi fabricado, primeiramente, a partir da calcinação de argilas cauliníticas. Recentemente, esta pozolana tem sido obtida por meio da moagem e calcinação de argilas especiais (caulim de alta pureza), em baixas temperaturas, sendo um material com alta atividade pozolânica, MCAR [9]. Com relação ao aspecto químico, tanto para o metacaulim quanto para o MCAR, devem-se focar dois pontos principais: a sua composição química e a sua estrutura interna. Quanto à composição química, estes materiais têm, geralmente, proporções semelhantes de $\mathrm{SiO}_{2}$ e $\mathrm{Al}_{2} \mathrm{O}_{3}$, em massa [11]. A caulinita, mineral que dá nome ao grupo das argilas cauliníticas, apresenta uma composição química teórica de, aproximadamente, 39,8\% $\mathrm{Al}_{2} \mathrm{O}_{3}, 46,3 \%$ $\mathrm{SiO}_{2}$ e $13,9 \% \mathrm{H}_{2} \mathrm{O}$ [17]. A sua composição química, mesmo não sendo um parâmetro adequado para a avaliação da pozolanicidade, pois impossibilita a diferenciação entre a sílica cristalina e a não-cristalina, apresenta-se como uma forma de controle de produção ou de recepção da argila, com relação à sua origem ou procedência [18-19]. Para as pozolanas do tipo MCAR têm-se, na Tabela II, algumas exigências químicas, estabelecidas em normas [20- 22]. Mesmo não se tendo uma norma específica referente ao MCAR, acredita-se que os padrões definidos na Tabela III, estão adequados a esta pozolana, haja vista não ser este o fator principal de diferenciação entre o metacaulim e o MCAR. Dentre os valores colocados na Tabela III que talvez devam ter alteração quando se visa à utilização do MCAR são os referentes à somatória $\left(\mathrm{SiO}_{2}+\mathrm{Al}_{2} \mathrm{O}_{3}+\mathrm{Fe}_{2} \mathrm{O}_{3}\right)$ que deve ser superior a $90 \%$ e, o da perda de fogo, em torno de $3 \%$ [9].

Quanto ao aspecto microestrutural, as argilas cauliníticas, que se apresentam como as mais apropriadas para a obtenção do metacaulim devem ter as suas estruturas cristalinas

Tabela II - Especificações químicas para materiais pozolânicos do tipo do metacaulim [20-22].

[Table II - Chemical specifications for metakaolin pozzolan materials [20-22].]

\begin{tabular}{lccc}
\hline & $\mathrm{IS}$ & $\mathrm{ASTM}$ & $\mathrm{NBR}$ \\
Exigências químicas & 1344 & $\mathrm{C}-618$ & 12653 \\
& {$[21]$} & {$[20]$} & {$[22]$} \\
\hline $\left.\mathrm{SiO}_{2}+\mathrm{Al}_{2} \mathrm{O}_{3}+\mathrm{Fe}_{2} \mathrm{O}_{3}\right)-$ mín. & $70 \%$ & $70 \%$ & $70 \%$ \\
$\mathrm{SiO}_{2}-$ mín. & $40 \%$ & - & - \\
$\mathrm{CaO}-$ máx. & $10 \%$ & - & - \\
$\mathrm{MgO}-$ máx. & $3 \%$ & - & - \\
$\mathrm{SiO}_{3}-$ máx. & $3 \%$ & $4 \%$ & $4 \%$ \\
$\mathrm{Na}_{2} \mathrm{O}+\mathrm{K}_{2} \mathrm{O}-$ máx. & $3 \%$ & - & - \\
Teor de umidade - máx. & - & $3 \%$ & $3 \%$ \\
Álcalis solúveis em água - máx. & $0,1 \%$ & - & - \\
Álcalis disponíveis em $\mathrm{Na}_{2} \mathrm{O}-$ máx. & - & $1,5 \%$ & $1,5 \%$ \\
Material solúvel em água - máx. & $1 \%$ & - & - \\
Perda ao fogo - máx. & $5 \%$ & $10 \%$ & $10 \%$ \\
\hline
\end{tabular}

Tabela III - Composição química típica do MCAR [9]. [Table III- Typical MCAR chemical composition [9].]

\begin{tabular}{cc}
\hline $\begin{array}{c}\text { Composição típica } \\
\text { do metacaulim }\end{array}$ & Porcentagem em massa \\
\hline $\mathrm{SiO}_{2}$ & 51,52 \\
$\mathrm{Al}_{2} \mathrm{O}_{3}$ & 40,18 \\
$\mathrm{Fe}_{2} \mathrm{O}_{3}$ & 1,23 \\
$\mathrm{CaO}$ & 2,00 \\
$\mathrm{MgO}$ & 0,12 \\
Álcalis & 0,53 \\
Perda ao fogo & 2,01 \\
\hline
\end{tabular}

constituídas por unidades lamelares, sendo cada unidade formada por uma folha tetraédrica de silicato $\left(\mathrm{SiO}_{4}\right)$ e uma folha octaédrica de gibsita, cujas unidades $\mathrm{Al}(\mathrm{OH})_{3}$ estão ligadas entre si pelos átomos de oxigênio em comum [18]. Esta estrutura, quando sujeita ao tratamento térmico entre $400{ }^{\circ} \mathrm{C}$ e $550{ }^{\circ} \mathrm{C}$, tem o seu arranjo atômico destruído pela desidroxilação e, se apresenta em estrutura amorfa. Este processo térmico é essencial para o desenvolvimento da atividade pozolânica por parte das argilas [23]. As reações pozolânicas entre a metacaulinita e o $\mathrm{CH}$ são reações de dissolução com formação de novas fases. Devido ao grande desequilíbrio físico-químico (desordenação atômica) oriundo do tratamento térmico, a metacaulinita ao entrar em contato com o meio fortemente alcalino das pastas hidratadas de cimento Portland ( $\mathrm{pH}$ em torno de 13,5), provoca a dissolução do silício e do alumínio na superfície de suas partículas, que, posteriormente, reagem com o excesso de cálcio existente, cristalizando em aluminatos, silicatos e aluminossilicatos de cálcio hidratado [24]. O material para ser classificado como pozolana de alta reatividade deve combinar dois fatores [9]: uma estrutura amorfa e uma grande área específica. As principais exigências físicas estabelecidas em normas para este tipo de pozolana estão listadas na Tabela IV [20-22].

Quanto ao MCAR, há uma tendência pelo uso de material com menor quantidade de partículas retidas na peneira $0,045 \mathrm{~mm}$ e uma maior superfície específica para que possam assegurar o desempenho especificado para este tipo de pozolana [13, 23-24]. Nos concretos com MCAR

Tabela IV - Especificações físicas para a pozolana do tipo do metacaulim [20-22].

[Table IV - Physical specifications for metakaolin pozzolan [20-22].]

\begin{tabular}{cccc}
\hline Exigências físicas & $\begin{array}{c}\text { IS 1344 } \\
{[21]}\end{array}$ & $\begin{array}{c}\text { ASTM } \\
\text { C 618 } \\
{[20]}\end{array}$ & $\begin{array}{c}\text { NBR } \\
12653 \\
{[22]}\end{array}$ \\
\hline $\begin{array}{c}\text { Material retido na peneira } \\
\text { 0,045 mm, máx. }\end{array}$ & 12 & 34 & 34 \\
$\begin{array}{c}\text { Superficie específica, } \\
\text { Blaine, mín. }\left(\mathrm{m}^{2} / \mathrm{kg}\right)\end{array}$ & 320 & \\
\hline
\end{tabular}


têm-se, assim como na sílica ativa, os efeitos microfiler de nucleação e de densificação da zona da transição decorrentes da elevada finura deste material sintetizado [24-29].

Efeito das pozolanas altamente reativas em materiais cimentícios

A introdução de pozolanas altamente reativas no concreto resulta em uma série de alterações em suas propriedades, tanto no estado fresco quanto no estado endurecido.

No estado fresco: a) consumo de água. Aumenta em argamassas e concretos para uma dada consistência com o emprego das pozolanas altamente reativas [9]; b) trabalhabilidade. Em estudos de dosagem com teores de adição de sílica ativa da ordem de $2 \%$ a $3 \%$, em relação à massa do cimento, foram constatados aumentos na trabalhabilidade do concreto. Este resultado foi atribuído à forma esférica do material [30]; c) aspectos reológicos. A coesão da mistura é controlada pelo volume de pasta presente no concreto. Assim sendo, tem-se com a substituição em massa de cimento por pozolanas com menor massa específica, o aumento da quantidade de pasta, o que resulta numa melhoria do aspecto reológico da mistura. Esta melhoria está diretamente relacionada ao menor diâmetro das partículas destas pozolanas, haja vista que reduz o tamanho e o volume dos vazios [2].

No estado endurecido: a) resistência à compressão. A ação química e física das pozolanas de alta reatividade produz, normalmente, a melhoria da resistência à compressão e a durabilidade do concreto devido, principalmente, ao processo de refinamento dos poros e dos cristais presentes na pasta de cimento hidratada [2]. A contribuição da sílica ativa para a resistência à compressão do concreto está diretamente relacionada a diversos fatores, tais como: teor na mistura, suas características mineralógicas, físicas e químicas; composição do cimento, relação água/(cimento+pozolana), (relação $\mathrm{a} /(\mathrm{c}+\mathrm{a})$ ), tipo e dosagem de superplastificante, temperatura, umidade, dosagem e processo de cura submetido ao concreto [9]. Dal Molin [5], adotando um teor de adição de 10\% de sílica ativa sobre a massa de cimento, obteve aos 28 dias, uma melhoria média, dentre as diversas relações a/(c+a) estudadas, de $13,51 \%$. Quanto à quantidade consumida de sílica ativa no concreto, Malhotra e Metha [2] chegaram à conclusão de que o teor ótimo varia de $7 \%$ a $10 \%$, podendo, em algumas situações especiais, chegar a teores de $15 \%$. Estes valores são muito semelhantes aos sugeridos por Aïtcin [31], de 8\% a 10\% da massa de cimento. Em todos os casos estudados consensouse pelo uso de aditivos superplastificantes em paralelo ao uso destas pozolanas altamente reativas [2]; b) resistência à tração. O uso de 10\% de sílica ativa causou aumentos médios na resistência à tração por compressão diametral de $21,74 \%$ e, de apenas, $4,15 \%$ na resistência à tração na flexão aos 28 dias, dentre as diversas relações a/(c+a) estudadas [5]. A pouca eficiência do efeito da sílica ativa, na flexão, foi creditada à menor área específica do corpo-de-prova submetido à tração, onde a sílica ativa teve um papel fundamental. Com teores de substituição $>10 \%$ foi observado decréscimo nos resultados de resistência à tração por compressão diametral [32-33].

\section{EXPERIMENTAL}

Procurou-se estabelecer uma relação de testes no concreto e seus materiais constituintes de maneira que as principais características das misturas fossem representadas.

Os corpos-de-prova (CP) foram moldados para a determinação das propriedades mecânicas nas idades de 7 , 28 e 90 dias, sendo três CPs de uma mesma betonada para

Tabela V - Testes físico-químicos e mecânicos no concreto e agregados.

[Table V-Physicochemical and mechanical tests in concrete and aggregates.]

\begin{tabular}{|c|c|}
\hline Concreto & Norma equivalente \\
\hline Resistência à Compressão Axial simples & NBR 5739 [34] \\
\hline Resistência à tração por compressão diametral & NBR 7222 [35] \\
\hline Massa específica do concreto fresco & NBR 7223 [36] \\
\hline Ar incorporado do concreto fresco & NBR 9833 [37] \\
\hline Consistência pelo abatimento tronco de cone & NBR NM 67 [38] \\
\hline Moldagem e cura de corpos-de-prova & NBR 5738 [39] \\
\hline \multicolumn{2}{|l|}{ Agregado } \\
\hline Abrasão Los Angeles & NBR 6465 [40] \\
\hline Absorção d'água no agregado miúdo & NBR 9777 [41] \\
\hline Absorção d'água no agregado graúdo & NBR 9937 [42] \\
\hline Granulometria dos agregados & NBR 7217 [43] \\
\hline Massa específica do agregado miúdo & NBR 9776 [44] \\
\hline Massa específica do agregado graúdo & NBR 9937 [42] \\
\hline Reatividade potencial álcali-agregado & ASTM C-1260 [45] \\
\hline Teor de Materiais pulverulentos & NBR $7211[46]$ \\
\hline Teor de umidade do agregado & NBR 9939 [47] \\
\hline
\end{tabular}


Tabela VI - Testes físico-químicos e mecânicos no cimento, materiais cimentícios e aditivo.

[Table VI - Physicochemical and mechanical tests in cement, cimentitious materials and additive.]

\begin{tabular}{ll}
\hline Cimento e materiais cimentícios & Norma equivalente \\
\hline Análise química cimentos comuns & NBR 9203 [48] \\
Expansibilidade Le Chatelier & NBR 11582 [49] \\
Finura peneira 200 & NBR 11579 [50] \\
Finura peneira 325 & NBR 12826 [51] \\
Finura Blaine & NBR NM 76 [52] \\
Massa Específica & NBR 6474 [53] \\
Cimento Portland - Resistência à & NBR 7215 [54] \\
compressão & NBR 1158 [55] \\
Tempo de pega & NBR NM 23 [56] \\
Massa específica material pozolânico & \\
\hline \multicolumn{2}{c}{ Aditivo } \\
\hline Densidade, pH e resíduo sólido & NBR 10908 [57] \\
\hline
\end{tabular}

cada idade, com o objetivo de avaliar o desvio padrão dentro do ensaio.

Os principais testes físico-químicos e mecânicos realizados sobre os insumos e o concreto encontram-se apresentados com suas respectivas especificações técnicas nas Tabelas V e VI. A incerteza de medição adotada para a resistência à compressão e à tração por compressão diametral foi de $0,5 \%$.

Foi utilizado o cimento Portland composto tipo CP IIZ 32, de um mesmo lote de fabricação. As características físicas, químicas e mecânicas do cimento empregado foram obtidas a partir de informações do fabricante e demais resultados dos testes listados na Tabela VI. A areia artificial e os agregados graúdos utilizados foram de origem basáltica, oriundos da britagem do agregado para a obra do Aproveitamento Hidroelétrico Espora, em Aporé-GO. Antes de sua utilização o material foi preparado, deixandoo próximo da condição de superfície saturada seca. A água empregada foi proveniente da rede de abastecimento, sendo que sua quantidade foi mantida proporcional à manutenção da mesma trabalhabilidade de cada mistura.

Adições minerais. O MCAR utilizado foi composto de matéria-prima extraída na região sul de Minas Gerais e, a sílica ativa, produto industrializado na região norte do Brasil, no Estado do Pará. Ambos foram trabalhados isoladamente, com teores equivalentes a $8 \%$ em relação ao cimento.

Dosagem do concreto. No estudo, foi utilizado o método do módulo de finura [58-59]. Neste método aborda-se, como princípio, a Lei de Slater-Lyse, onde "quaisquer agregados que possuam o mesmo módulo de finura, não obstante eles possam ter diferentes porcentagens de tamanhos individuais, produzirão concretos de consumo de água iguais ou muito próximos entre si e a trabalhabilidade substancialmente igual" [59].

No controle da trabalhabilidade foi adotado o valor de $(70 \pm 10) \mathrm{mm}$ para o ensaio de abatimento de tronco de cone [38]. A fixação do abatimento foi o referencial para a obtenção do teor de água.

Para a produção do concreto foi empregada uma betoneira de eixo vertical. Teve-se o cuidado de imprimir o seu interior com a argamassa do mesmo traço do concreto antes de cada betonada. A colocação dos materiais transcorreu seguindo esta ordem: i) $100 \%$ de agregado graúdo e miúdo, mais $50 \%$ de água (sem aditivo); e, ii) 100\% de aglomerante; e, $50 \%$ de água e aditivo. Após a colocação de todos os materiais, foi realizada a mistura por $3 \mathrm{~min}$, seguido de um período de descanso de 3 min e mais 2 min de mistura. Foram moldados três CPs para testes nas idades de 7, 28 e 90 dias, para cada variável e para a idade de controle, analisadas. Para a execução da moldagem foi utilizado o adensamento mecânico, com uso do vibrador de imersão de agulha de $19 \mathrm{~mm}$ de diâmetro. Após o procedimento, os CPs foram cobertos e mantidos no ambiente da sala de dosagens, protegidos por uma fina película plástica durante, aproximadamente, $24 \mathrm{~h}$. Terminadas as primeiras $24 \mathrm{~h}$, os CPs foram retirados das formas sendo, então, colocados na câmara úmida, com umidade relativa superior a $95 \%$ e temperatura de $(23 \pm 2){ }^{\circ} \mathrm{C}$, até o momento de realização de cada ensaio. Para o rompimento dos mesmos, visando à determinação da resistência à compressão, foi feito capeamento com enxofre e pó de quartzo, na proporção de 1: 0,3 , respectivamente. Esta combinação visou ao aumento da resistência e maior durabilidade do capeamento. Em cada dosagem foi empregado o aditivo superplastificante à base de naftaleno sulfonato, constituído de $37 \%$ a 39\% de sólidos, densidade de $1,2 \mathrm{~kg} / \mathrm{m}^{3}$ e na proporção recomendada pelo fabricante de $1,0 \%$ em relação à massa de cimento.

Relação entre custos. Foram considerados os custos dos insumos de maior valor unitário, sendo: i) cimento: $\mathrm{R} \$ 0,35 /$ kg; ii) MCAR: R \$ 0,60/kg; iii) sílica ativa: R\$ 1,00/kg; e, iv) aditivo polifuncional: $\mathrm{R} \$ 1,00 / \mathrm{kg}$ [60]. Todos estes valores foram avaliados em função dos respectivos consumos obtidos nos estudos de dosagem, mantendo-se constante o parâmetro da resistência à compressão.

Eficiência Econômica, EE, (R\$.MPa) $/\left(\mathrm{kg} \cdot \mathrm{m}^{-3}\right)$, dos concretos com adições em relação ao RC. $\mathrm{O}$ valor respectivo foi calculado em função da resistência à compressão $(\mathrm{R})$, dividida pelo consumo de aglomerantes (cimento, $\mathrm{C}$, + adição, A), sendo ambos multiplicados pelos respectivos custos unitários $(\mathrm{CC}=$ custo cimento e $\mathrm{CA}=$ custo da adição), conforme apresentado na Equação A.

$$
\mathrm{EE}=\mathrm{R} /(\mathrm{C} . \mathrm{CC}+\mathrm{A} \cdot \mathrm{CC})
$$

\section{RESULTADOS E DISCUSSÃO}

Características físicas dos agregados. O teor de material pulverulento no agregado miúdo foi obtido acima do especificado [46], podendo o concreto resultante estar sujeito ao desgaste superficial. Tal valor também foi considerado na dosagem. O restante dos ensaios teve seus resultados dentro das recomendações de norma. 
Reatividade potencial. Na Fig. 1, está apresentado o gráfico da reatividade potencial, segundo método ASTM C1260 [45], sem e com o uso das adições minerais à base de $8 \%$ de sílica ativa e de $8 \%$ de MCAR, isoladamente em cada dosagem, em relação ao peso do cimento. Observou-se que, sem o uso das adições minerais, o material se apresentou reativo, com coeficiente de expansão linear aos 16 e aos 28 dias superiores ao recomendado em norma [45]. Ambos

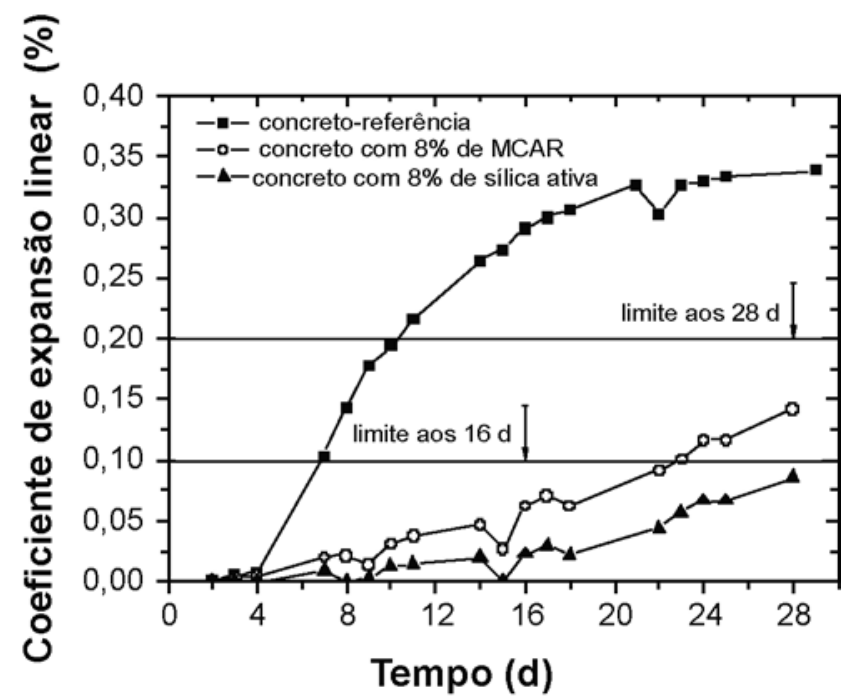

Figura 1: Reatividade potencial álcali-agregado, medido segundo as recomendações da norma ASTM C1260 [45].

[Figure 1: Alkali-aggregate potential reactivity measured as ASTM C1260 recommendation [45].] os limites estão mostrados com suas respectivas linhas horizontais (mais espessas) no gráfico: em $0,1 \%$ aos 16 dias; e, $0,2 \%$, aos 28 dias. As adições minerais, na proporção utilizada para ambas as pozolanas foram suficientes para mitigar ou inibir a reação, reduzindo o conficiente de expansão resultante aos limites recomendados [45, 61-62]. Entretanto, observaram-se expansões maiores em idades mais avançadas de ensaio, já aos 24 dias, não se podendo inferir nenhuma estimativa, com precisão, da vida útil da estrutura. As características físico-químicas informadas pelo fabricante para a sílica ativa e para o MCAR foram consideradas satisfatórias para seus empregos em dosagens de concreto.

Propriedades das dosagens dos concretos fresco $e$ endurecido. Nas Tabelas VII a XIX, encontram-se reunidos os resultados das composições e testes obtidos para os traços de concreto sem adição (concreto-referência) e com MCAR e sílica ativa, respectivamente. Destaca-se para o MCAR, em relação às dosagens do concreto-referência, que houve uma redução do consumo de água unitária com ganho de trabalhabilidade.

Resistência à compressão axial. Os valores obtidos foram proporcionais à idade de cura e ao teor de adição mineral e, inversamente, proporcional à relação $\mathrm{a} /(\mathrm{c}+\mathrm{a})$. Os resultados obtidos para a resistência à compressão das três composições trabalhadas e quatro módulos de finura, estão apresentados nas Figs. 2 e 3 . O desempenho dos concretos com adições minerais apresentaram ganhos de resistência superiores ao RC em todas as idades analisadas. Os resultados foram equivalentes e menores do que $5 \%$ em todas as idades e módulo de finura 1: $\mathrm{m}$.

Tabela VII - Composição e ensaios do concreto no estado fresco, RC.

[Table VII - RC composition and tests results from fresh mixes.]

\begin{tabular}{|c|c|c|c|c|c|}
\hline \multirow{4}{*}{ 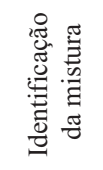 } & \multirow{4}{*}{$\begin{array}{l}\text { Dosagem } \\
\text { Identificação } \\
\text { Ar incorporado solicitado }(\%) \\
\text { Slump solicitado }(\mathrm{mm})\end{array}$} & \multicolumn{4}{|c|}{ Dmáx $25 \mathrm{~mm}$ - slump entre 60 e 70} \\
\hline & & E-2271 & E-2272 & E-2273 & E-2274 \\
\hline & & $1,0 \pm 0,5$ & $1,0 \pm 0,5$ & $1,0 \pm 0,5$ & $1,0 \pm 0,5$ \\
\hline & & $70 \pm 10$ & $70 \pm 10$ & $70 \pm 10$ & $70 \pm 10$ \\
\hline \multirow{14}{*}{ 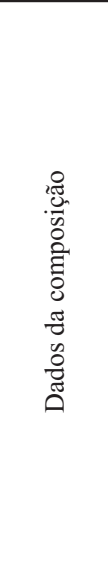 } & m (relação 1: m) & 12 & 9 & 6 & 3 \\
\hline & Cimento $\left(\mathrm{kg} / \mathrm{m}^{3}\right)$ & 183 & 239 & 341 & 598 \\
\hline & MCAR ou sílica ativa (\%) & 0 & 0 & 0 & 0 \\
\hline & Água $\left(\mathrm{kg} / \mathrm{m}^{3}\right)$ & 188 & 178 & 166 & 174 \\
\hline & Areia $\operatorname{artificial}\left(\mathrm{kg} / \mathrm{m}^{3}\right)$ & 965 & 913 & 808 & 556 \\
\hline & Brita $25 \mathrm{~mm}\left(\mathrm{~kg} / \mathrm{m}^{3}\right)$ & 1236 & 1238 & 1238 & 1238 \\
\hline & $\operatorname{Aditivo~}\left(\mathrm{kg} / \mathrm{m}^{3}\right)$ & 1,834 & 2,390 & 3,411 & 5,979 \\
\hline & Relação $(\mathrm{a} / \mathrm{c}+\mathrm{p})$ & 1,03 & 0,74 & 0,49 & 0,29 \\
\hline & Areia $(\% \mathrm{p} / \mathrm{p})$ & 43,8 & 42,4 & 39,5 & 30,9 \\
\hline & Módulo de finura & 3,92 & 4,02 & 4,22 & 4,82 \\
\hline & Massa específica teórica $\left(\mathrm{kg} / \mathrm{m}^{3}\right)$ & 2598 & 2616 & 2636 & 2626 \\
\hline & Temperatura ambiente $\left({ }^{\circ} \mathrm{C}\right)$ & 24,9 & 24,9 & 24,4 & 24,7 \\
\hline & Temperatura do cimento $\left({ }^{\circ} \mathrm{C}\right)$ & 23,4 & 23,4 & 24,4 & 24,4 \\
\hline & Temperatura da água $\left({ }^{\circ} \mathrm{C}\right)$ & 22,9 & 22,9 & 22,4 & 22,4 \\
\hline \multirow{4}{*}{ 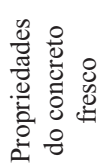 } & Abatimento (cm) & 65 & 70 & 70 & 65 \\
\hline & Ar incorporado (\%) & 2,5 & 2,5 & 3,0 & 2,5 \\
\hline & Massa específica $\left(\mathrm{kg} / \mathrm{m}^{3}\right)$ & 2587 & 2574 & 2552 & 2568 \\
\hline & Temperatura $\left({ }^{\circ} \mathrm{C}\right)$ & 24,8 & 23,9 & 24,4 & 25,7 \\
\hline
\end{tabular}


Tabela VIII - Composição e ensaios do concreto no estado fresco, com 8\% p/p MCAR. [Table VIII - 8\% w/w MCAR composition and tests results from fresh mixes.]

\begin{tabular}{|c|c|c|c|c|c|}
\hline \multirow{4}{*}{ 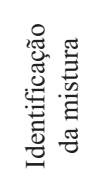 } & \multirow{2}{*}{$\begin{array}{c}\text { Dosagem } \\
\text { Identificação }\end{array}$} & \multicolumn{4}{|c|}{ Dmáx $25 \mathrm{~mm}$ - slump entre 60 e 70} \\
\hline & & E-2275 & E-2276 & E-2277 & E-2278 \\
\hline & Ar incorporado solicitado (\%) & $1,0 \pm 0,5$ & $1,0 \pm 0,5$ & $1,0 \pm 0,5$ & $1,0 \pm 0,5$ \\
\hline & Slump solicitado (mm) & $70 \pm 10$ & $70 \pm 10$ & $70 \pm 10$ & $70 \pm 10$ \\
\hline \multirow{14}{*}{ 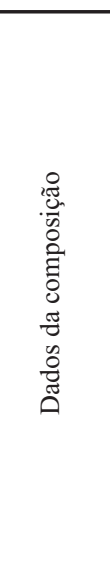 } & m (relação 1: m) & 12 & 9 & 6 & 3 \\
\hline & Cimento $\left(\mathrm{kg} / \mathrm{m}^{3}\right)$ & 169 & 220 & 316 & 549 \\
\hline & $\operatorname{MCAR}\left(\mathrm{kg} / \mathrm{m}^{3}\right)$ & 15 & 19 & 27 & 48 \\
\hline & Água $\left(\mathrm{kg} / \mathrm{m}^{3}\right)$ & 184 & 170 & 168 & 173 \\
\hline & Areia artificial $\left(\mathrm{kg} / \mathrm{m}^{3}\right)$ & 969 & 915 & 813 & 555 \\
\hline & Brita $25 \mathrm{~mm}\left(\mathrm{~kg} / \mathrm{m}^{3}\right)$ & 1242 & 1240 & 1245 & 1234 \\
\hline & Aditivo $\left(\mathrm{kg} / \mathrm{m}^{3}\right)$ & 1,842 & 2,390 & 3,430 & 5,960 \\
\hline & Relação (a/c+p) & 1,00 & 0,71 & 0,49 & 0,29 \\
\hline & Areia $(\% \mathrm{p} / \mathrm{p})$ & 43,8 & 42,4 & 39,5 & 30,9 \\
\hline & Módulo de finura & 3,92 & 4,02 & 4,22 & 4,82 \\
\hline & Massa específica teórica $\left(\mathrm{kg} / \mathrm{m}^{3}\right)$ & 2603 & 2626 & 2630 & 2619 \\
\hline & Temperatura ambiente $\left({ }^{\circ} \mathrm{C}\right)$ & 21,4 & 19,9 & 19,9 & 20,0 \\
\hline & Temperatura do cimento $\left({ }^{\circ} \mathrm{C}\right)$ & 19,3 & 19,3 & 18,3 & 19,3 \\
\hline & Temperatura da água $\left({ }^{\circ} \mathrm{C}\right)$ & 19,3 & 18,3 & 18,3 & 18,3 \\
\hline \multirow{4}{*}{ 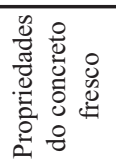 } & Abatimento $(\mathrm{cm})$ & 65 & 65 & 70 & 60 \\
\hline & Ar incorporado (\%) & 1,0 & 2,5 & 2,5 & 2,5 \\
\hline & Massa específica $\left(\mathrm{kg} / \mathrm{m}^{3}\right)$ & 2578 & 2565 & 2571 & 2560 \\
\hline & Temperatura $\left({ }^{\circ} \mathrm{C}\right)$ & 20,3 & 18,7 & 19,3 & 19,4 \\
\hline
\end{tabular}

Tabela IX - Composição e ensaios do concreto no estado fresco, com $8 \% \mathrm{p} / \mathrm{p}$ de sílica ativa. [Table IX - 8\% w/w silica fume-concrete composition and tests results from fresh mixes].

\begin{tabular}{|c|c|c|c|c|c|}
\hline \multirow{4}{*}{ 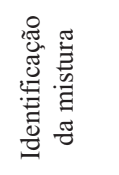 } & \multirow{2}{*}{$\frac{\text { Dosagem }}{\text { Identificação }}$} & \multicolumn{4}{|c|}{ Dmáx $25 \mathrm{~mm}$ - slump entre 60 e 70} \\
\hline & & E-2279 & E-2280 & E-2281 & E-2282 \\
\hline & Ar incorporado solicitado (\%) & $1,0 \pm 0,5$ & $1,0 \pm 0,5$ & $1,0 \pm 0,5$ & $1,0 \pm 0,5$ \\
\hline & Slump solicitado (mm) & $70 \pm 10$ & $70 \pm 10$ & $70 \pm 10$ & $70 \pm 10$ \\
\hline \multirow{14}{*}{ 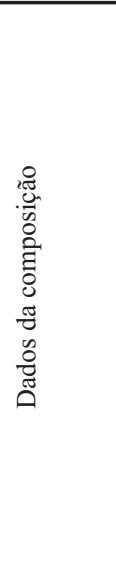 } & m (relação 1: m) & 12 & 9 & 6 & 3 \\
\hline & Cimento $\left(\mathrm{kg} / \mathrm{m}^{3}\right)$ & 169 & 220 & 316 & 544 \\
\hline & Sílica ativa $\left(\mathrm{kg} / \mathrm{m}^{3}\right)$ & 15 & 19 & 28 & 47 \\
\hline & Água $\left(\mathrm{kg} / \mathrm{m}^{3}\right)$ & 179 & 174 & 167 & 180 \\
\hline & Areia artificial $\left(\mathrm{kg} / \mathrm{m}^{3}\right)$ & 968 & 918 & 815 & 550 \\
\hline & Brita 25 mm $\left(\mathrm{kg} / \mathrm{m}^{3}\right)$ & 1241 & 1245 & 1248 & 1225 \\
\hline & Aditivo $\left(\mathrm{kg} / \mathrm{m}^{3}\right)$ & 1,840 & 2,400 & 3,440 & 5,920 \\
\hline & Relação (a/c+p) & 0,98 & 0,72 & 0,49 & 0,31 \\
\hline & Areia (\% p/p) & 43,8 & 42,4 & 39,5 & 30,9 \\
\hline & Módulo de finura & 3,92 & 4,02 & 4,22 & 4,82 \\
\hline & Massa específica teórica $\left(\mathrm{kg} / \mathrm{m}^{3}\right)$ & 2608 & 2618 & 2627 & 2604 \\
\hline & Temperatura ambiente $\left({ }^{\circ} \mathrm{C}\right)$ & 20,4 & 18,1 & 20,0 & 21,0 \\
\hline & Temperatura do cimento $\left({ }^{\circ} \mathrm{C}\right)$ & 19,3 & 16,2 & 20,0 & 21,0 \\
\hline & Temperatura da água $\left({ }^{\circ} \mathrm{C}\right)$ & 18,3 & 16,2 & 19,5 & 20,0 \\
\hline \multirow{4}{*}{ 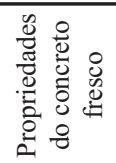 } & Abatimento $(\mathrm{cm})$ & 60 & 65 & 65 & 65 \\
\hline & Ar incorporado (\%) & 1,0 & 2,5 & 1,5 & 1,0 \\
\hline & Massa específica $\left(\mathrm{kg} / \mathrm{m}^{3}\right)$ & 2570 & 2585 & 2570 & 2537 \\
\hline & Temperatura $\left({ }^{\circ} \mathrm{C}\right)$ & 19,8 & 18,2 & 20,0 & 21,0 \\
\hline
\end{tabular}

Consumo de cimento. Para verificar o efeito da adição mineral no consumo de cimento para as diferentes resistências, foram estipuladas resistências do concreto de 20, 25, 30, 35 e $40 \mathrm{MPa}$, por serem, normalmente, as utilizadas em grandes obras de engenharia, notoriamente, as barragens de usinas hidroelétricas. Os resultados encontramse apresentados nas Figs. 4 e 5, onde, nas ordenadas é apresentado o consumo de aglomerantes e, nas abscissas, a 


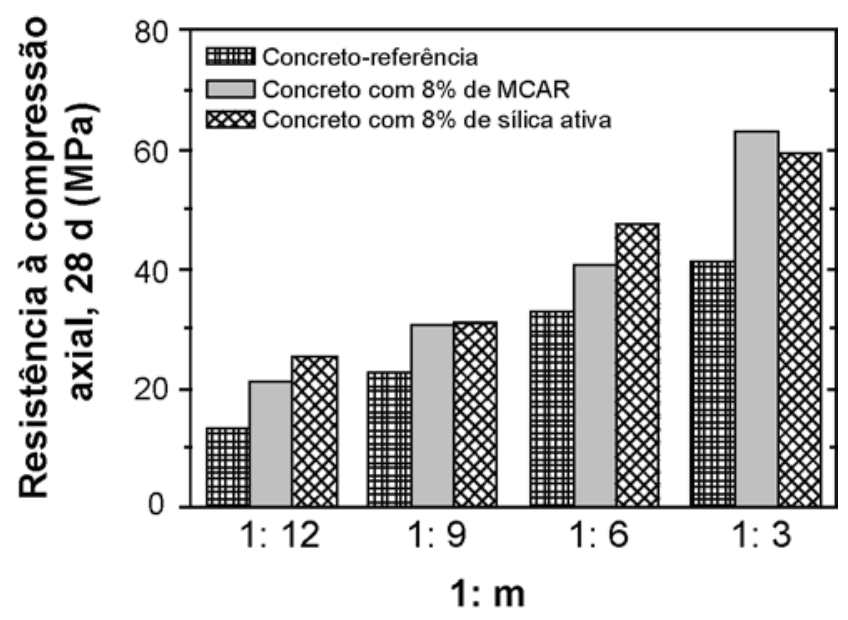

Figura 2: Resistência à compressão aos 28 dias pela relação 1: $\mathrm{m}$. [Figure 2: Compression strength on 28 days, as a function of 1: $\mathrm{m}$.]

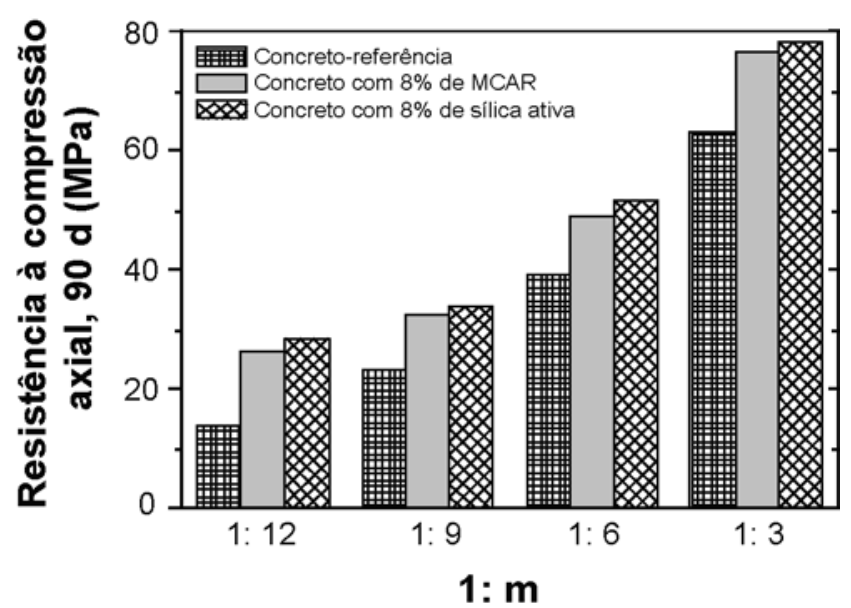

Figura 3: Resistência à compressão aos 90 dias pela relação $1: \mathrm{m}$. [Figure 3: Compressive strength on 90 days as a function of 1: $\mathrm{m}$.]

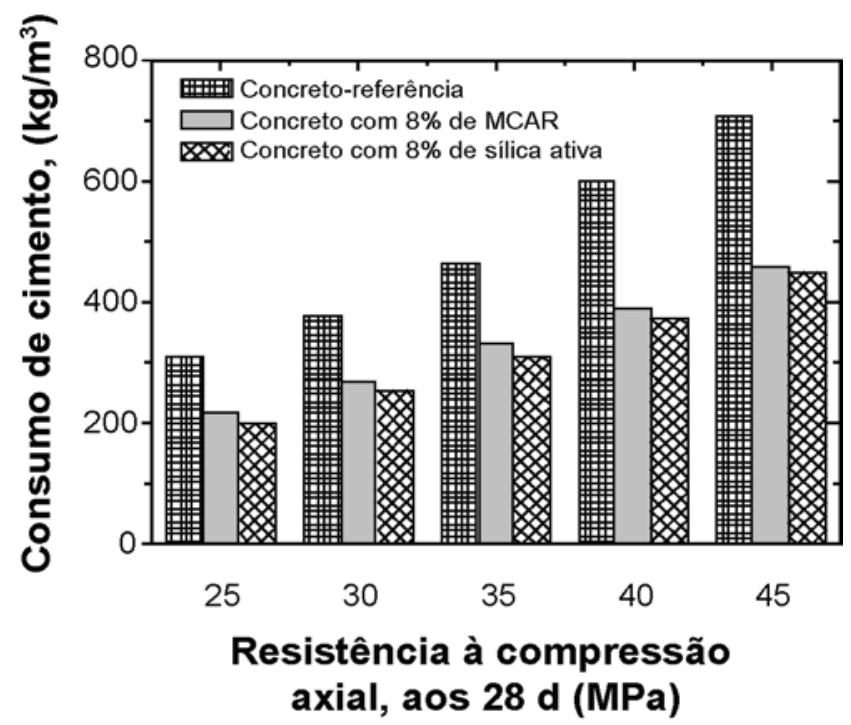

Figura 4: Consumo de cimento e adição mineral pela resistência especificada, aos 28 dias.

[Figure 4: Cement consumption and mineral admixtures as function of compressive strength on 28 days.]

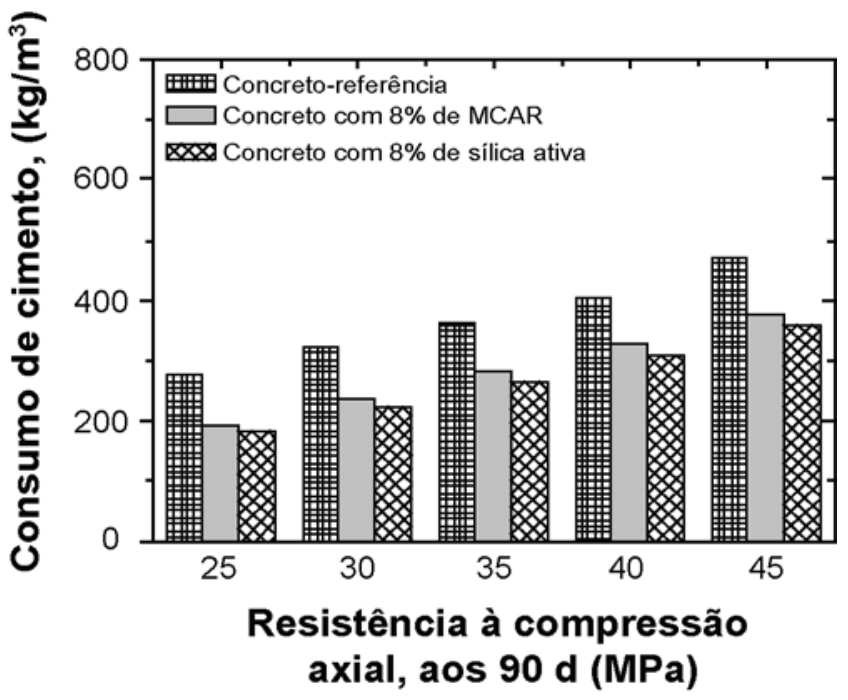

Figura 5: Consumo de cimento e adição mineral pela resistência especificada, aos 90 dias.

[Figure 5: Cement consumption and mineral admixtures as function of compressive strength on 90 days.]

resistência mecânica à compressão para as idades de 28 e 90 dias, respectivamente. Foram constatadas diferenças de valores no consumo de cimento e adições para todas as dosagens analisadas, ou seja, a introdução dos teores de MCAR e da sílica ativa nos concretos estudados provocou redução geral nos consumos de cimento. Este fato ficou mais evidente aos 90 dias devido ao ganho de resistência nesta idade em relação aos 28 dias. A adição dos minerais em função da idade na resistência à compressão do concreto resultou em valores superiores aos encontrados no RC e estão em acordo com os dados apresentados na literatura [5, 25].

Resistência à tração por compressão diametral. Os valores obtidos dos ensaios sobre o concreto-referência, com $8 \%$ de MCAR e com $8 \%$ de sílica ativa para os 28 e 90 dias, estão apresentados nas Figs. 6 e 7, respectivamente. Constatou-se, novamente, um comportamento proporcional à idade e ao teor de substituição e inversamente proporcional à relação a/(c + a). Os desempenhos dos concretos com adição mineral foram ligeiramente superiores aos obtidos com o $\mathrm{RC}$, em todas as idades e módulo de finura, trabalhados. A ordem de grandeza das diferenças obtidas entre os resultados de resistência à tração por compressão diametral entre as dosagens de referência, comparadas com as dosagens com adição mineral, não foram significativas, confirmando os resultados de Paulon [63].

Relação entre custos. Considerando o custo unitário equivalente a $100 \%$ para as dosagens do RC e o cálculo dos custos secundários com as adições minerais, foram obtidas as reduções de custo com a utilização do MCAR e da sílica ativa, resultando em $27,8 \%$ e $25,8 \%$, aos 28 dias e, de $21,0 \%$ e $17,7 \%$, aos 90 dias, respectivamente.

A análise demonstrou que os concretos com MCAR e sílica ativa tiveram, em termos de resistência à compressão até os 90 dias, bom desempenho e sempre superior ao do 


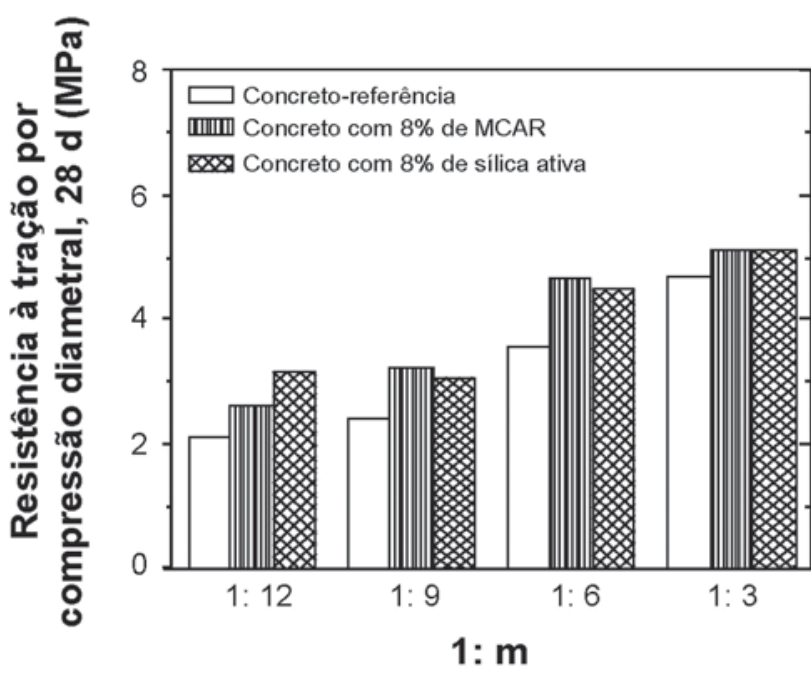

Figura 6 : Resistência à tração por compressão diametral aos 28 dias pela relação $1: \mathrm{m}$.

[Figure 6 :Tensile strength by diametrical compression on 28 days, relation $1: \mathrm{m}$.]

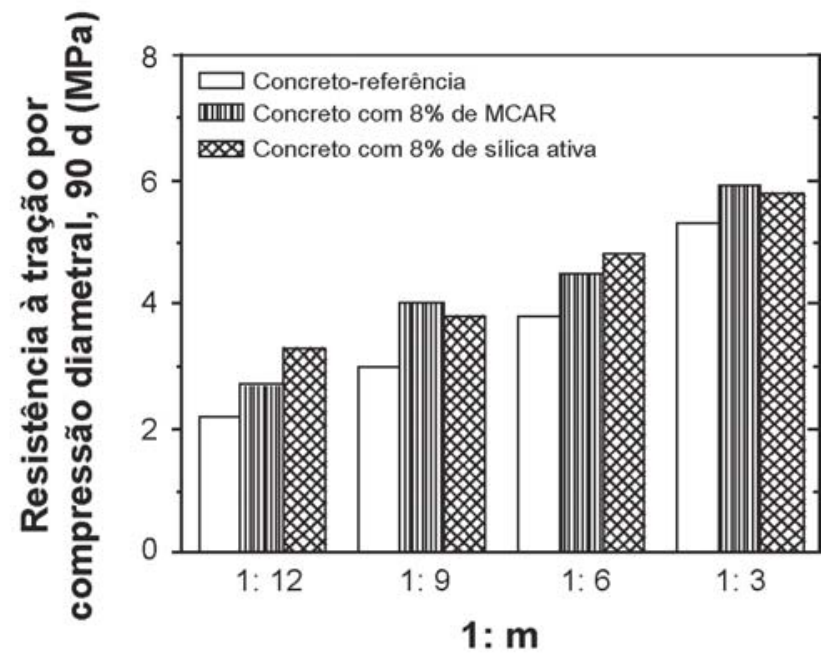

Figura 7 : Resistência à tração por compressão diametral aos 90 dias pela relação $1: \mathrm{m}$.

[Figure 7: Tensile strength by diametrical compression on 90 days, relation $1: \mathrm{m}$.]

RC. Em virtude do custo da sílica ativa ter sido superior ao do MCAR, no momento de suas compras, sua EE foi menor em cerca de 4\%. Observa-se que devem ser considerados os preços praticados no mercado, na época de realização da análise comparativa.

Observou-se, também, que aos 90 dias o RC, apresentou crescimento de EE em relação aos 28 dias na medida em que a resistência dos concretos foi aumentada. Isso pode ser explicado devido ao cimento conter $15 \%$ de pozolana do tipo "fly ash". Essa adição tendeu a promover ganhos de resistência maiores na idade de 90 dias em relação à idade de 28 dias.

\section{CONCLUSÕES}

A resistência à compressão dos concretos obtidos gerou uma série de correlações que comprovaram o benefício da adição mineral ao RC. Independentemente do consumo de aglomerantes, dentre os valores analisados, o benefício da utilização de adições minerais contribuiu, favoravelmente, para a redução de custos e melhoria da qualidade das resistências mecânicas analisadas. Os concretos compostos com sílica ativa e com o MCAR apresentaram melhores desempenhos do que o RC em termos de trabalhabilidade das misturas e em relação às propriedades mecânicas investigadas. A relação custo/benefício do emprego das adições minerais foi favorável. Em todas as dosagens estudadas houve economia em relação ao RC. Este valor teve redução em $17,7 \%$ aos 90 dias. A partir dos 7 dias de idade observou-se ganho discreto das resistências mecânicas investigadas tanto para o MCAR quanto para a sílica ativa, em relação às dosagens do RC. Entretanto, após 28 dias, essa diferença se tornou mais evidente. Pelo método do módulo de finura foi possível avaliar, experimentalmente, as diferenças entre as dosagens e estabelecer, sob as mesmas condições experimentais, as diferenças entre os concretos sem e com adição.

\section{AGRADECIMENTOS}

Ao LACTEC e ao Programa Interdisciplinar de PósGraduação em Engenharia da UFPR pela infra-estrutura e pelo apoio financeiro para a execução deste projeto de pesquisa. Também aos produtores dos insumos disponibilizados para o estudo.

\section{REFERÊNCIAS}

[1] P. K. Mehta, Concrete International 21, 11 (1999) 47.

[2] P. K. Mehta, P. J. M. Monteiro, Concreto: estrutura, propriedades e materiais. PINI, S. Paulo, SP (1994).

[3] Rilem Technical Reports, Mater. Structure 21, 121 (1988) 69.

[4] A. M. Neville, S. E. Giammusso, Propriedades do concreto, 2a Ed., PINI, S. Paulo, SP (1997).

[5] D. C. C. Dal Molin, Tese de Doutorado, Escola Politécnica da Universidade de S. Paulo, SP (1995).

[6] C. V. Gomes Filho, Dissertação de Mestrado, PRODETEC, Curitiba, PR (2007).

[7] C. Freitas, Dissertação de Mestrado, PIPE, UFPR, Curitiba, PR (2007).

[8] V. P. Della, I. Kühn, D. Hotza, Quím. Nova 24 (2001) 6. [9] V. M. Malhotra, P. K. Mehta, Pozzolanic and cementicious materials - advances in concrete technology, vol.1, Gordon and Breach, Amsterdam, Holanda (1996).

[10] B. B. Sabir, S. Wild, J. Bai, Cem. Conc. Compos. 23 (2001) 441.

[11] http://www.ecoplan.org.br/port/projetos/ram02.html, acessado em 10/08/2007.

[12] ACI Mater. J. Comm. 226, 84 (1987) 2. 
[13] M. A. Caldarone, K. A. Gruber, Proc. Concrete under Severe Conditions, Sapporo, Japão (1995).

[14] F. M. Lea, The chemistry of cement and concrete, $3^{\mathrm{a}}$ Ed., Chem. Publ., Londres, UK (1971).

[15] Associação Brasileira de Normas Técnicas, NBR 13956, ABNT, Rio de Janeiro ( 1997).

[16] G. R. B. de Sensale, Tese de Doutorado, Universidade Federal do Rio Grande do Sul, RS (2000).

[17] C. F. Gomes, Argilas - o que são e para que servem, Fund. Calouste Gulbenkian, Lisboa, Portugal (1988).

[18] R. E. Grim, Applied clay mineralogy, McGraw-Hill, New York, EUA (1962).

[19] P. S. Santos, Ciência e Tecnologia de Argilas, 2a Ed., Edgard Blücher, S. Paulo, SP (1992).

[20] American Association for Testing and Materials, C 61891, ASTM, Philadelphia, EUA (1991).

[21] Indian Standards Institution, IS 1344, New Delhi, India(1968).

[22] Associação Brasileira de Normas Técnicas, NBR 12653, ABNT, Rio de Janeiro, RJ (1992).

[23] C. He, B. Osbaeck, E. Markovicky, Cem. Conc. Res. 25 (1995) 1691.

[24] V. A. Zampieri, Dissertação de Mestrado, Universidade de S. Paulo, SP (1989).

[25] M. A. Caldarone, K. A. Gruber, R.G. Burg, Concrete Int. 16 (1994) 37.

[26] M. H. Zhang, V. M. Malhotra, Cem. Conc. Res. 25 (1995) 1713.

[27] J. M. Khatib, S. Wild, Cem. Conc. Res. 26 (1996) 1545.

[28] R. M. de G. Delvasto, R. T. Morales, Materiales de construcción $\mathbf{5 0}$ (2000) 5.

[29] C. S. Poon, L. Lam, S.C. Kou, Y. L. Wong, R. Wong, Cem. Conc. Res. 31 (2001) 1301.

[30] G. G. Carette, V. M. Malhotra, Proc. ACI 132 (1993).

[31] P. C. Aïtcin, High-Performance Concrete, Université de Sherbrooke, Canada (1998).

[32] B. B. Sabir, Conc. Res. 47 (1995) 219.

[33] M. F. Moraes, Dissertação de Mestrado, Escola Politécnica da Universidade de S. Paulo, SP (1990).

[34] Associação Brasileira de Normas Técnicas, NBR 5739, ABNT, Rio de Janeiro, RJ (1980).

[35] Associação Brasileira de Normas Técnicas, NBR 7222, ABNT, Rio de Janeiro, RJ 1(994).

[36] Associação Brasileira de Normas Técnicas, NBR 7223, ABNT, Rio de Janeiro, RJ (1992).

[37] Associação Brasileira de Normas Técnicas, NBR 9833, ABNT, Rio de Janeiro, RJ 1987.

[38] Associação Brasileira de Normas Técnicas, NM 67, ABNT, Rio de Janeiro, RJ (1998).

[39] Associação Brasileira de Normas Técnicas, NBR 5738,
ABNT, Rio de Janeiro, RJ (1994).

[40] Associação Brasileira de Normas Técnicas, NBR 6465, ABNT, Rio de Janeiro, RJ (1984).

[41] Associação Brasileira de Normas Técnicas, NBR 9777, ABNT, Rio de Janeiro, RJ (1987).

[42] Associação Brasileira de Normas Técnicas, NBR 9937, ABNT, Rio de Janeiro, RJ (1987).

[43] Associação Brasileira de Normas Técnicas, NBR 7217, ABNT, Rio de Janeiro, RJ (1987).

[44] Associação Brasileira de Normas Técnicas, NBR 9776, ABNT, Rio de Janeiro, RJ (1986).

[45] American Association for Testing and Materials, C 1260-94, ASTM, West Conshohocken, EUA (1994).

[46] Associação Brasileira de Normas Técnicas, NBR 7211, ABNT, S. Paulo, SP (1983).

[47] Associação Brasileira de Normas Técnicas, NBR 9939, ABNT, Rio de Janeiro, RJ (1987).

[48] Associação Brasileira de Normas Técnicas, NBR 9203, ABNT, Rio de Janeiro, RJ (1985).

[49] Associação Brasileira de Normas Técnicas, NBR 11582, ABNT, Rio de Janeiro, RJ (1985).

[50] Associação Brasileira de Normas Técnicas, NBR 11579, ABNT, Rio de Janeiro, RJ (1991).

[51] Associação Brasileira de Normas Técnicas, NBR 12826, ABNT, Rio de Janeiro, RJ (1993).

[52] Associação Brasileira de Normas Técnicas, NM 76, ABNT, Rio de Janeiro, RJ (1998).

[53] Associação Brasileira de Normas Técnicas, NBR 6474, ABNT, Rio de Janeiro, RJ (1984).

[54] Associação Brasileira de Normas Técnicas, NBR 7215, ABNT, Rio de Janeiro, RJ (1991).

[55] Associação Brasileira de Normas Técnicas, NBR 1158, ABNT, Rio de Janeiro, RJ (1991).

[56] Associação Brasileira de Normas Técnicas, NM 23, ABNT, Rio de Janeiro, RJ (1998).

[57] Associação Brasileira de Normas Técnicas, NBR 10908, ABNT, Rio de Janeiro, RJ (1986).

[58] W. P. Andrade, J. T. Fontoura, E. A. Guerra, R. M. Bittencourt, Um método de dosagens para concreto-massa, IBRACON, S. Paulo, SP (1981).

[59] W. PAndrade, Concretos Massa, Estrutural, Compactado com Rolo e Projetado - Propriedades. PINI: S. Paulo, SP (1997).

[60] J. B. M. do Carmo, Dissertação de Mestrado. Universidade Federal do Paraná, PR (2006).

[61] N. P. Hasparyk, Dissertação de Mestrado, Universidade Federal de Goiás, GO (1999).

[62] A. Joukoski, K. F. Portella, O. Baron, C. M. Garcia, G. R. Vergés, A. Sales, J. F. de Paula, Cerâmica, 50, 313 (2004) 12.

[63] V. A. Paulon, F. L. Ibraim, Anais 37a Reunião Anual do IBRACON, Goiânia, GO (1995).

(Rec. 08/10/2007, Ac. 24/01/2008) 